\title{
Inducible Maize Defense Mechanisms Against the Corn Borer Sesamia nonagrioides: A Transcriptome and Biochemical Approach
}

\author{
Víctor M. Rodríguez, Rogelio Santiago, Rosa Ana Malvar, and Ana Butrón \\ Misión Biológica de Galicia, Spanish Council for Scientific Research (CSIC), Apartado 28, E-36080 Pontevedra, Spain
}

Submitted 7 June 2011. Accepted 2 September 2011.

\begin{abstract}
In spite of multiple studies elucidating individual defense mechanisms against stalk borer feeding, little information is available about the plant response to these members of Lepidoptera. Four maize inbred lines were cultivated in a greenhouse and challenged with larvae of the corn borer Sesamia nonagrioides. Transcriptome and biochemical analyses were performed to elucidate the maize response mechanisms to this insect. General plant defense mechanisms were activated, including the jasmonic acid biosynthetic pathway, proteinase inhibitors, and four defenserelated transcription factors. Interestingly, gene ontology analysis shows that maize plants undergo cell-wall reorganization after being attacked. These results were confirmed through biochemical analyses showing that the concentration of some cell-wall-related compounds significantly changed after plant infestation in a genotype-dependent way. In conclusion, maize plants respond to the attack of the corn borer $S$. nonagrioides through cell-wall fortification, activating genes involved in cell-wall organization, which finally is reflected in a higher concentration of some cell-wall components, especially in resistant genotypes.
\end{abstract}

Attack by mobile herbivores is the major biotic challenge plants have to cope with during their life cycle. Although not exclusively, the largest group of herbivores is phytophagous insects, which covers a diverse taxonomic group with more than one million species (Futuyma and Agrawal 2009). Primary plant defense against insects consists of physical barriers. Once these barriers are breached, inducible defense mechanisms are activated to reduce herbivore damage (Agrawal 1998). Phytophagous insects trigger two types of inducible responses in plants: direct defenses that retard insect growth and development and indirect defenses that involve the production of metabolites that attract parasitoids and predators (Govind et al. 2010). Therefore, plants respond to insect feeding through an extensive transcriptome reprogramming and activation of defense mechanisms to improve plant survival. In recent decades, technical advances in genomic transcript profiling methods have allowed considerable progress in elucidating plant-defenseinducible mechanisms (Hermsmeier et al. 2001; Wan et al. 2002). A comprehensive analysis of the transcriptome response

V. Rodríguez and R. Santiago contributed equally to this work.

Corresponding author: V. M. Rodríguez; Telephone: +34 9868548 00; Fax:+34986841362; E-mail: vmrodriguez@mbg.csic.es

* The $e$-Xtra logo stands for "electronic extra" and indicates that a supplementary table is published online. in Nicotiana attenuata, a wild relative of tobacco, identified several gene families as being activated in response to insectinflicted damage, including several transcriptional regulators and protein kinases (Gilardoni et al. 2010; Hermsmeier et al. 2001). Similar results were observed in other plant species (Reymond et al. 2004; Wei et al. 2009). Plant responses to defoliators have been broadly characterized in a number of different plant species (Kaur et al. 2010; Philippe et al. 2009; Reymond et al. 2004) but, in contrast, little is known about the plant response to attack by other herbivores such as stalk borers.

"Stalk borers" include a number of moth species that attack the stalk of poaceous plants. The larvae of these members of Lepidoptera penetrate into the stalk and feed in the plant's pith tissues, resulting in crop losses, early leaf senescence, and interference with translocation of metabolites (Kfir et al. 2002). Individual inducible mechanisms have been reported to be involved in plant defense against these insects. For instance, silencing of the 13-lipoxygenase OsHI-LOX, which encodes an enzyme in the jasmonic acid (JA) biosynthetic pathway, makes rice plants more susceptible to the attack by the stalk borer Chilo supressalis (Walker), suggesting an important role of the hormone JA in resistance against this arthropod (Zhou et al. 2009).

In maize (Zea mays L.), several mechanisms of resistance against stalk borers have been reported (Malvar et al. 2008). In the particular case of Sesamia nonagrioides, structural resistance factors such as rind thickness or pith and rind puncture were not correlated with maize resistance (Santiago et al. 2003). The most outstanding resistance mechanisms are those involving the compound 2,4-dihydroxy-7-methoxy-1,4-benzoxazin3-one (DIMBOA) (Klun et al. 1967; Reid et al. 1991; Robinson et al. 1982) and the increased stiffness of the pith cell wall (Santiago et al. 2006). DIMBOA along with its derivates is likely to be the major factor explaining resistance in juvenile stages (Oikawa et al. 2004; Robinson et al. 1982). However, because DIMBOA levels are thought to decrease as the plant grows, little is known about the putative role that this compound could play in the maize stalk at the reproductive stage. At this stage, the maize cell wall is the major plant structure involved in defense against stalk damage by borers. The functional role of this structure depends on its composition and organization of individual components. The primary cell wall of the grasses is built of a skeleton of cellulosic microfibrils embedded in a matrix composed mainly of hemicelluloses and smaller amounts of pectins and glycoproteins (Carpita et al. 2001). Likewise, maize has high levels of ferulic and $p$-coumaric acids ester linked to cell-wall polymers (Ishii 1997). The secondary cell wall contains a wide range of additional compounds which include lignin. In the presence of phenolic- 
carbohydrate complexes, fiber strength increases, providing a tougher physical barrier to restrict insect penetration and render nutrients within tissues less accessible (Bergvinson et al. 1997; Santiago et al. 2008). Almost all the published works in this area have been related to the involvement of the constitutive amounts of these components in resistance against stalk borers. However, little is known about the role of cell-wall components as inducible defense mechanisms.

A transcriptome profiling analysis was performed in order to identify the inducible defense mechanisms in the maize stalk involved in the response to the attack of the corn borer $S$. nonagrioides. Due to the high genetic variability of maize, rather than just analyze the performance of one genotype across different treatments and replicates, four genetically independent maize inbred lines were used in the transcriptome analysis as biological replicates. In addition to the general plant-defense mechanisms to insect and pathogens, the major group of genes upregulated belongs to the cell-wall organization and biogenesis category. Genes involved in organization of the secondary growth of the cell wall were upregulated in the maize stalk internode, suggesting a fortification of this structure in response to stalk borer feeding. These results were confirmed by quantifying the levels of different cell-wall structural components in control and after corn borer attack. In addition, the levels of DIMBOA were quantified in the maize stalk internode, showing that, at least in one inbred line (EP39), this hydroxamic acid may have remarkable antibiosis activity in the maize stalk at the reproductive stage.

\section{RESULTS}

Transcriptome analysis of maize stalk internode challenged with $S$. nonagrioides caterpillars.

Gene expression profiling was performed to identify those genes differentially expressed in maize after infestation with the corn borer $S$. nonagrioides. Based on a thorough statistical analysis, 94 genes were considered significantly upregulated and two genes downregulated (Supplementary Table S1). No information is available about the molecular function of these two genes. The list of upregulated genes was divided into 12 categories according to the MaizeSequence database. The major group of genes upregulated is related to plant defense. These genes are mainly proteinase inhibitors (PI): four belong to the Bowman-Birk family, two are putative serine-type proteinase inhibitors, and three are cystatins. Three pathogenesisrelated (PR) genes were upregulated by insect feeding. Although the PR proteins are involved in pathogen-related defense, some of them are also wound-inducible (Graham et al. 2003). Also, seven plant chitinases were upregulated after insect feeding.

Another major group of genes upregulated after caterpillar attack corresponds to hormone biosynthesis and perception. Six of the eight hormone-related genes are involved in the octadecanoid biosynthetic pathway, which includes two genes involved in the biosynthesis of JA, a key hormone in plant anti-herbivore defense (12-OPDA reductase and allene oxide synthase $[A O S])$. The other three hormone-related genes upregulated are involved in the biosynthesis or perception of brassinosteroids and gibberellic acid.

Four transcripts encoding transcription factors (TF) were upregulated. Two of them belong to the WRKY superfamily, which is involved in many plant processes, including response to biotic and abiotic stresses (Zhang and Wang 2005). The $\mathrm{NAC1}$ and $\mathrm{CCCH}$ zinc-finger-containing motif proteins have been reported to play a role in auxine biosynthesis regulation and RNA processing in Arabidopsis and rice, respectively (Wang et al. 2008; Xie et al. 2002). A fourth group covers five upregulated genes involved in cell-wall metabolism (Table 1). Upregulation of typical cell-wall-related genes induced by herbivores such as expansins or cellulose synthases was not observed.

\section{Maize internode responds to $S$. nonagrioides feeding upregulating genes involved in cell-wall organization in a genotype-dependent way.}

Although it was not possible to statistically compare genotypes for gene expression patterns at individual transcripts due to the experimental approach, transcriptome-wide comparisons among inbreds can be made using the parametric analyses of gene set expression (PAGE) algorithm (Kim and Volsky 2005). The inbred line PB130 showed the highest transcriptome response to the attack (591 upregulated versus 348 downregulated genes) whereas the inbred line CM151 showed the lowest (201 versus 33 downregulated genes). This difference in the transcript expression profile was significant based on the $\chi^{2}$ test for homogeneity $(P<0.01)$. The PAGE analysis supplied information about the differential response of gene functional categories among inbreds, showing different strategies in the response to corn borer (Fig. 1). Three gene ontology (GO) categories were significantly (false discovery rate [FDR] < $0.05)$ upregulated in the four inbred lines: cell-wall organization or biogenesis, multiorganism process, and response to stimulus. In general terms, the higher response was shown by the cell-wall organization category. To a great extent, damage on the three resistant inbred lines (EP39, CM151, and PB130) changed the expression of the functional categories in the same direction, though these changes were quantitatively different. Interestingly, the inbreds EP39 and CM151 showed significant activation of the immune system process and death categories, suggesting that the hypersensitive response (HR) could play an important role as inducible defense mechanism in these genotypes. The inbred line PB130 is the one that responded the most to feeding and spent most of its resources in cell-wall fortification, even at the expense of other defense mechanisms (i.e., immune system process) (Fig. 1). The opposite behavior was observed in the susceptible inbred line EP42, which employs almost as many resources in cell-wall biogenesis

Table 1. Genes involved in cell wall metabolism significantly upregulated in the maize stem upon Sesamia nonagrioides feeding

\begin{tabular}{|c|c|c|c|c|}
\hline Description & Affymetrix probe set ID & $P$ value $^{\mathrm{a}}$ & $\log _{2}(\mathrm{FC})^{\mathrm{b}}$ & EST public ID \\
\hline \multicolumn{5}{|c|}{ Cell wall catabolism ${ }^{\mathrm{c}}$} \\
\hline$\beta-1,3$-Glucanase & Zm.6089.1.A1_at & 0.0086 & 1.7143 & BM381797 \\
\hline$\beta-1,3$-Glucanase & Zm.701.1.S1_s_at & 0.0105 & 3.0906 & AY111675.1 \\
\hline \multicolumn{5}{|c|}{ Cell wall reorganization or biogenesis ${ }^{\mathrm{d}}$} \\
\hline CCR2 & Zm.86.1.A1_at & 0.0093 & 2.2716 & Y1506901 \\
\hline Endochitinase A & $\mathrm{Zm} \cdot 1595.1 . \mathrm{S} 1$ at & 0.000 & 5.0819 & CD967190 \\
\hline $\mathrm{pCh} 2$ & Zm.847.1.S1_at & 0.0056 & 3.1339 & L00973.1 \\
\hline
\end{tabular}

${ }^{a} P$ values from the Student's $t$ test are shown.

${ }^{\mathrm{b}} \mathrm{FC}=$ fold change.

${ }^{\mathrm{c}}$ Gene ontology (GO) number 0016998.

${ }^{\mathrm{d}}$ GO number 0007047. 
as in activating genes involved in the response to stimulus or the immune system (Fig. 1). In contrast to resistant inbred lines, EP42 showed activation of the gene categories involved in metabolic processes and reproduction (Fig. 1).

Induction of cell-wall reorganization-related genes was confirmed by quantitative reverse-transcriptasepolymerase chain reaction (qRT-PCR).

The GO analysis points to massive cell-wall reorganization in the maize stalk after $S$. nonagrioides feeding. Five significantly upregulated transcripts were identified belonging to the cell-wall metabolism functional category. This category could be divided into two significant subcategories: cell-wall macromolecule catabolic process (GO: 0016998) and cellular cellwall organization (GO: 0007047) (Table 1). The former subcategory includes two $\beta$-1,3-glucanase transcripts involved in cellulose degradation. Most interestingly, the cellular cell-wall organization subcategory includes transcripts involved in the biosynthetic pathway of several compounds related to cell-wall formation (cinnamoyl CoA reductase 2 [CCR2], pCh2, and endochitinase A). To confirm the differential expression of this last set of genes, a qRT-PCR analysis was performed using four biological replicates of each genotype and treatment. In agreement with the microarray data, all three transcripts were highly and significantly upregulated across inbreds after insect feeding (data not shown). All genotypes tend to increase the expression of the three evaluated genes after insect feeding, albeit not significantly (Fig. 2). Nevertheless, the inbred line PB130 is the only one which significantly activates the expression for two of the three genes while CM151 increased significantly the expression of CCR2 after insect feeding (Fig. 2).

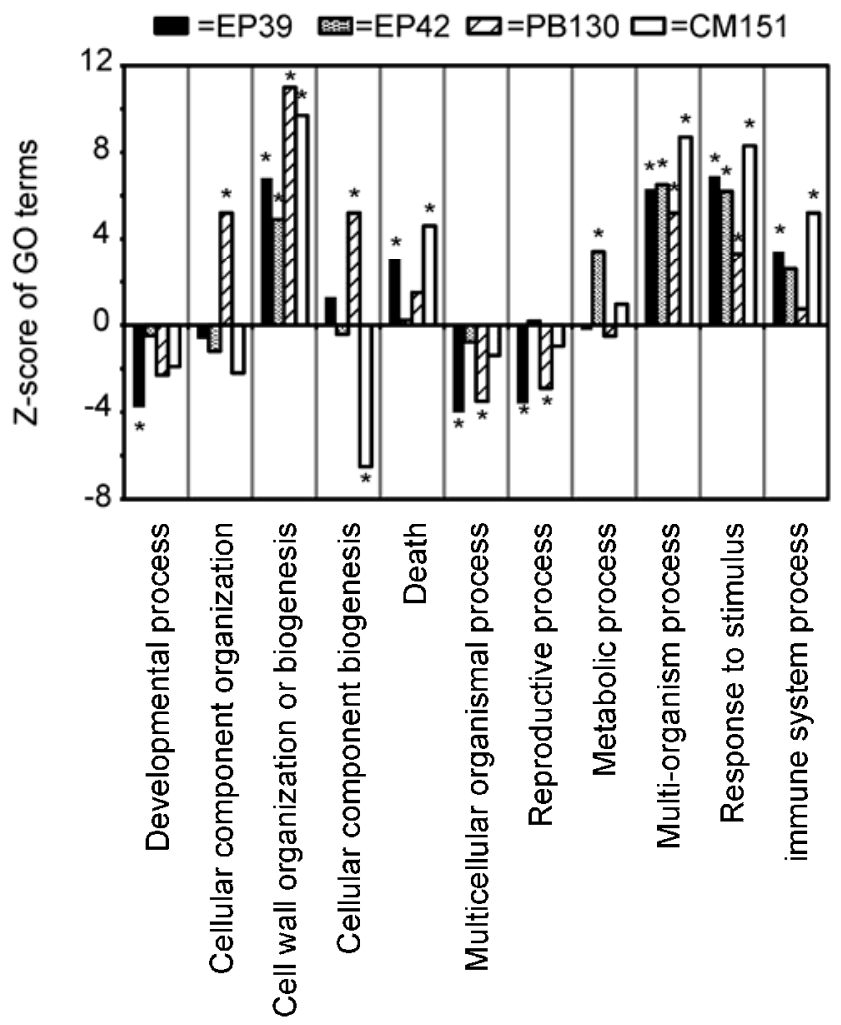

Fig. 1. Maize stalk undergoes cell wall reorganization after corn borer feeding. Gene ontology (GO) analysis of the response of four maize inbred lines to the attack of Sesamia nonagrioides. Gene expression for each inbred line was analyzed using the parametric analysis of gene set expression with a Hochberg false discovery rate (FDR) multitest adjusted method; * denotes an FDR $<0.05$.
Diferulate concentration significantly increases after corn borer attack.

The gene $C C R 2$ has been reported to be involved in phenylpropanoid metabolism, which includes the metabolic pathway for the synthesis of cell-wall-bound phenolics (Pichon et al. 1998). To get deeper insight in the role of the cell-wall compounds as inducible-defense mechanisms against $S$. nonagrioides, ester-bound phenolics ( $p$-coumarate, ferulate, and diferulates) previously identified to be related to corn borer resistance in maize (Santiago et al. 2006) and lignin content (Ostrander and Coors 1997) were quantified. In agreement with previous publications (Jung 2003; Santiago et al. 2006), $p$-coumarate and ferulate ester linked were more abundant than diferulates in the maize stalk in both control and infested plants. The level of $p$-coumarate averaged across inbreds significantly decreases in infested plants, whereas the level of

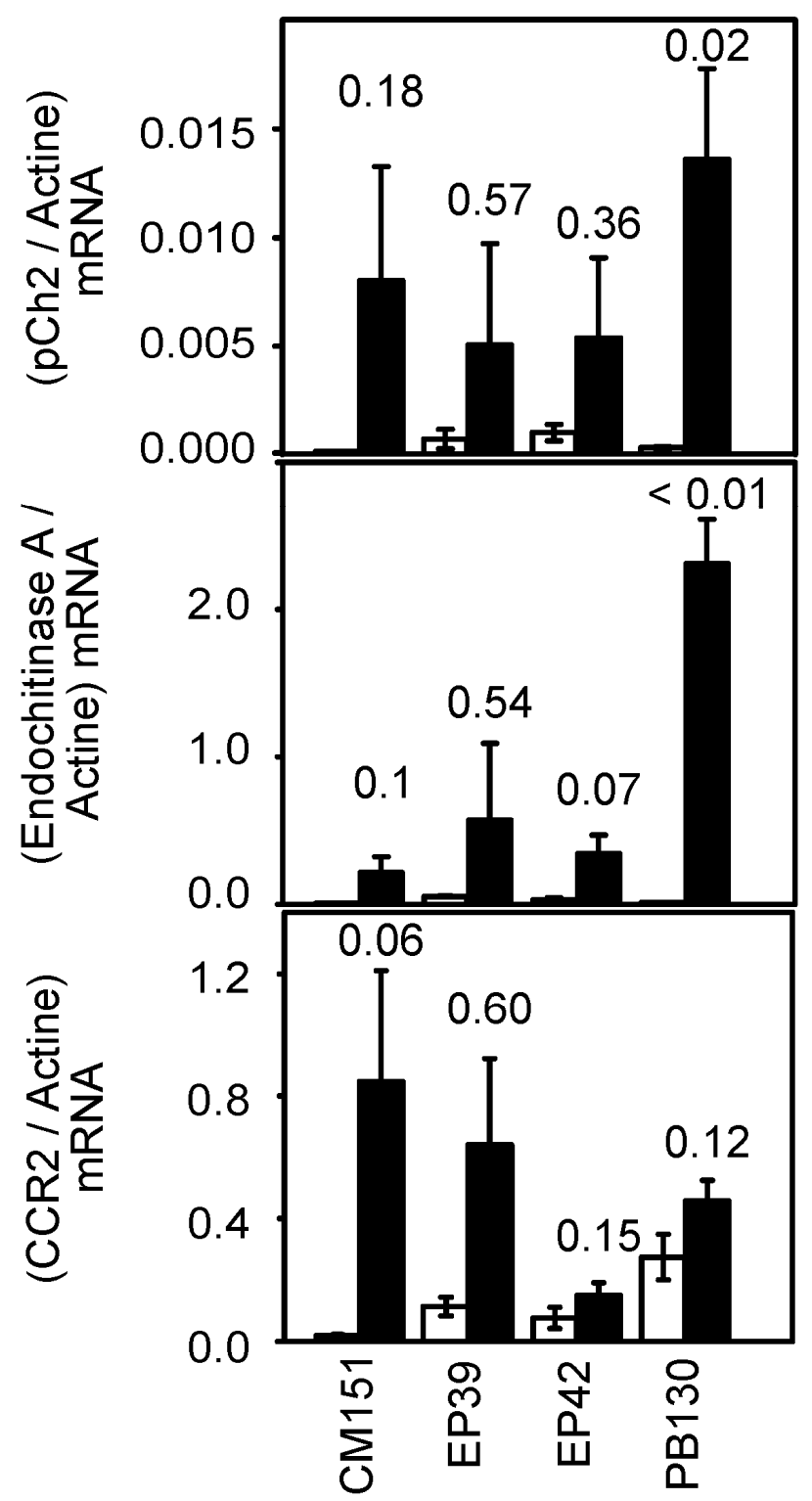

Fig. 2. Quantitative reverse-transcriptase polymerase chain reaction analysis of pCh2, endochitinase A, and CCR2 mRNAs in maize stalk after corn borer feeding. Expression of the three genes in each of the four inbred lines evaluated. For each inbred line, data are the average of four biological replicates and bars denote standard error ( \pm standard error). mRNA levels were calculated relative to the abundance of actin mRNA. $P$ values are shown above the bars. White bars, control treatment; black bars, Sesamia nonagrioides treatment. 
ferulate and diferulates increased after treatment (data not shown). Analysis of these compounds for individual inbred lines indicated that PB130 was the only one that had significantly increased levels of ferulate after insect attack, and this is largely responsible of the reported average increase in diferulates, because plants of this inbred line challenged with $S$. nonagrioides accumulate twice as much diferulate as control plants (Fig. 3A). Moreover, a significant decrease in the average amount of $p$-coumarate across inbreds after attack was observed, although that decrease was only significant for CM151 and PB130 (Fig. 3A).

To determine the effect of feeding on lignin content, the levels of acid detergent lignin (ADL) were quantified. Similarly to ester-bound cell-wall phenolics, the response to herbivore attack was genotype dependent and the levels of ADL increased significantly only in the inbred line CM151 (Fig. 3B).

\section{The inbred line EP39 shows high levels} of DIMBOA in the mature stem.

DIMBOA concentration has been reported to decrease dramatically with maize growing and its role in maize resistance

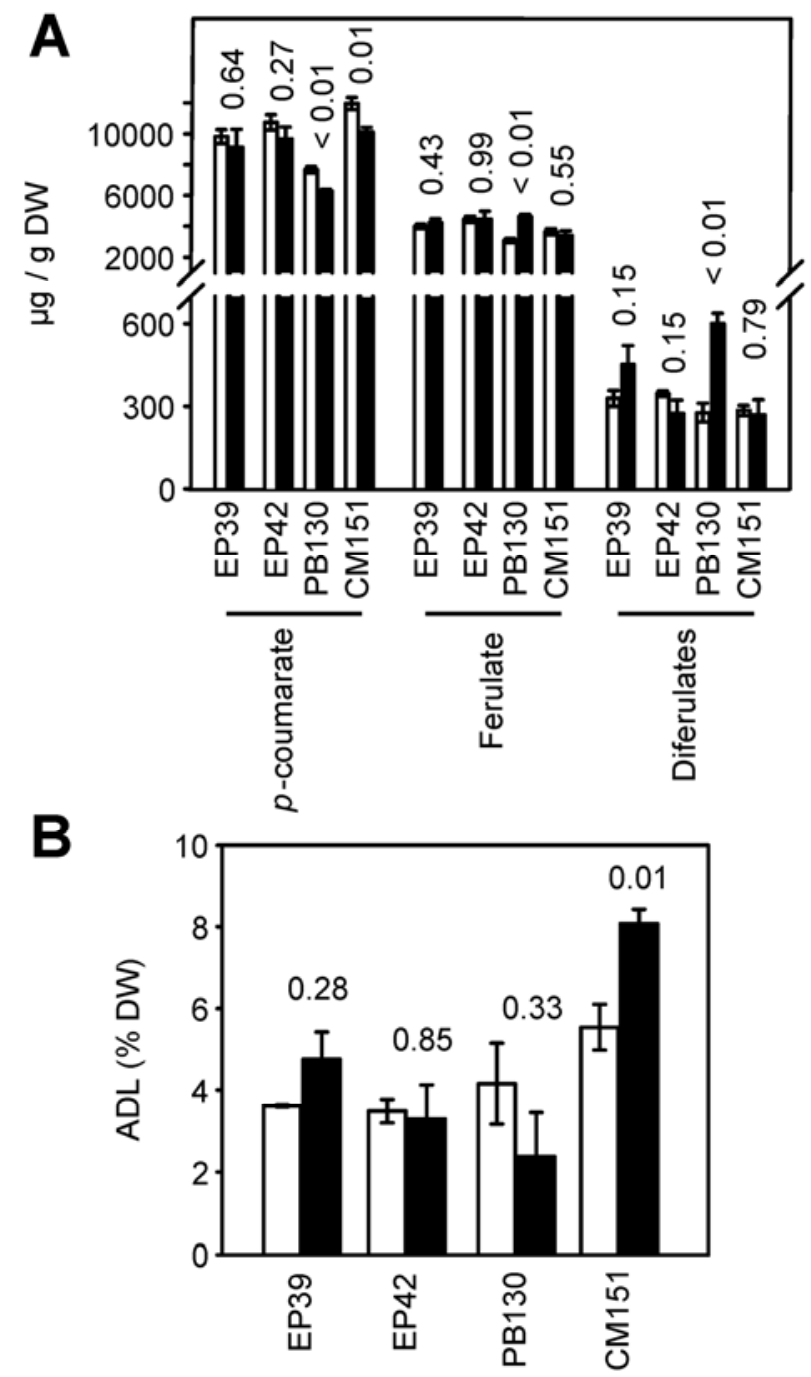

Fig. 3. Quantification of cell-wall-related components in four independent maize inbred lines. A, Levels of three cell-wall-esterified phenolic compounds in control conditions and after the attack of the corn borer Sesamia nonagrioides. B, Percentage of acid detergent lignin (ADL) in four maize inbred lines after corn borer attack. In all panels, values are means of four biological replicates \pm standard error. $P$ values are shown above the bars. White bars, control treatment; black bars, $S$. nonagrioides treatment. to stem attack by borers has been neglected. However, further confirmation of that hypothesis is necessary. To determine whether DIMBOA could be at bioactive levels in maize at reproductive stages and could have a role in the response of maize stalk against $S$. nonagrioides, the levels of this hydroxamic acid in this tissue in both control and infested plants were quantified. No differences were observed in the average content of DIMBOA between control and treated plants (440 \pm 125 versus $251 \pm 84 \mu \mathrm{g} / \mathrm{g}$ dry weight, respectively). The average DIMBOA levels across inbreds found in this experiment is in accordance with those reported previously (Bergvinson et al. 1997). These authors suggest that very low DIMBOA levels in the stalk during silking did not contribute to a second generation of corn borer resistance. However, analyzing the data of each individual inbred line, the EP39 showed significantly higher levels of DIMBOA than the other three inbred lines (Fig. 4). In addition, the EP39's stalk showed higher levels of DIMBOA than those reported previously in other genotypes (Bergvinson et al. 1997). Even though the concentration of DIMBOA is thought to decrease as the plant grows and, therefore, would not be able to protect the plant at the reproductive stage, the levels in the EP39's stalk could have noticeable antibiosis activity based on previous observations (Robinson et al. 1982).

\section{DISCUSSION}

Most transcriptome analyses performed on plant-insect interaction are carried out based on the performance of one genotype across different treatments and replicates. This strategy, however, yields limited information about general responses in highly variable plant species such as maize. This limitation prompted us to use four genetically unrelated maize inbred lines as biological replicates to identify general mechanisms through which the maize stalk responds to $S$. nonagrioides feeding. Like-

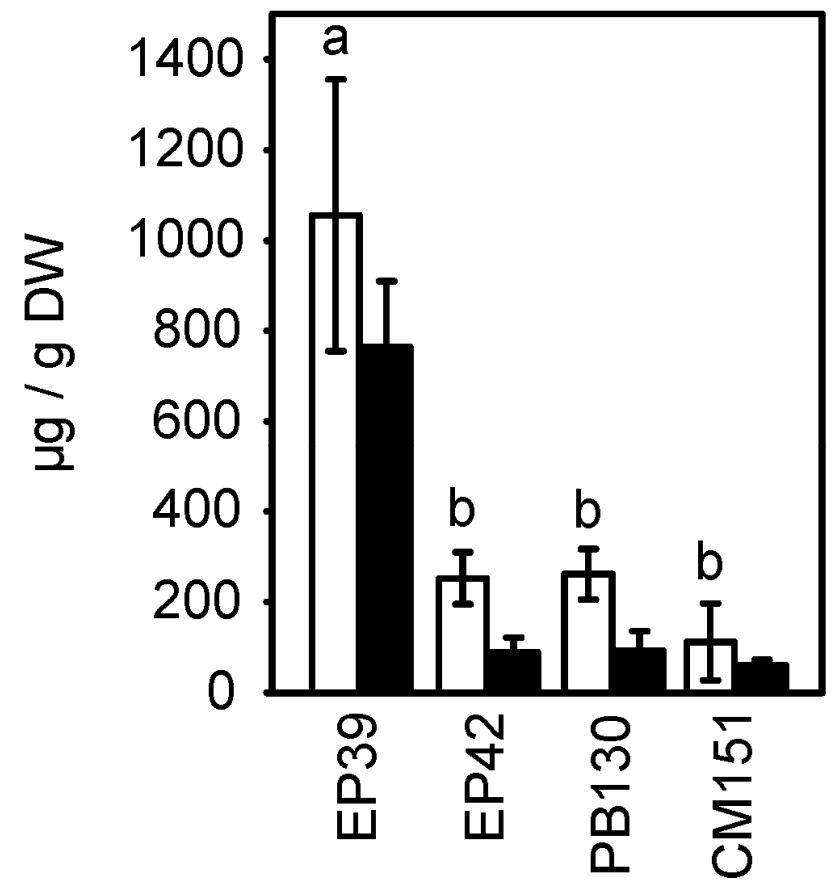

Fig. 4. Quantification of 2,4-dihydroxy-7-methoxy-1,4-benzoxazin-3-one (DIMBOA) in the maize stalk at the reproductive stage of control and infested plants. DIMBOA levels in four independent inbred lines in control conditions and after corn borer feeding. Values are means of four biological replicates \pm standard error. White bars, control treatment; black bars, Sesamia nonagrioides treatment. 
wise, contrary to most works carried out so far, which mainly used the whorl or the leaf, we used the maize stalk to perform the analysis because this is the major tissue of corn borer feeding. To the best of our knowledge, this is the first transcriptome profile analysis performed in cereal stalks to identify genes involved in response to stalk borer attack.

As expected, gene categories related to defense against other organisms were significantly induced. Most of the transcripts upregulated have been previously reported to respond to insect feeding; though this is the first time such activation is reported in the maize stalk. Within these categories, several transcripts involved in the synthesis or perception of phytohormones were significantly upregulated after corn borer injury, such as $A O S$, a gene involved in the synthesis of JA (Park et al. 2002). Curiously, two of the transcription factors upregulated are suggested to be involved in the JA-signaling pathway in Arabidopsis (Journot-Catalino et al. 2006; Xu et al. 2006). Along with previous observations (Zhou et al. 2009), the results presented herein confirm the central role of JA in activating a defense mechanism against stalk borers. Also, defense proteins, such as PI and PR proteins, were upregulated. Among them, the genes WIPl and MPI stand out. Expression of these genes is induced by wounding and fungal infection (Cordero et al. 1994; Rohrmeier and Lehle 1993).

GO analysis corroborated the overexpression of functional categories involved in plant defense. In addition, this analysis showed that maize plants undergo extensive cell-wall reorganization after $S$. nonagrioides larvae feeding. Though the magnitude of this reorganization seems to be genotype dependent, in all four genotypes, the activation of genes related to cell-wall metabolism is noticeable compared with other categories. For a more comprehensive analysis, this category was divided into two subcategories, cell-wall catabolism and cellular cell-wall organization. Within the first subcategory, there are genes involved in cellulose ( $\beta$-1,3-glucanases) degradation. This gene family is typically activated in plants to prevent insect feeding and pathogen invasion (Bowles 1990). More interestingly, the other subcategory includes three genes involved in cell-wall formation. According to Guillaumie and associates (2007), two of these upregulated genes are annotated as chitinase-like genes ( $p C h 2$ and Endochitinase A) (Table 1). These genes were identified through a subtractive macroarray approach to discover sets of cell-wall-related genes that exhibit internodestage preferential expression profiles. In agreement with that, studies on functional genomics in several plant species have shown that plant chitinase-like genes are compromised in cellwall development (Finaev 2007; Hermans et al. 2010; Zhang et al. 2004). The pCh2 protein has been demonstrated to have chitinase activity in vitro; however, tobacco plants transformed with the maize locus show higher early vigor than control plants (Patil and Widholm 1997), suggesting a biological role for this protein other than that on chitin degradation. The gene $C C R 2$ reduces precursors in the monolignol pathway from the acid to the aldehyde oxidation state. In tobacco and Arabidopsis plants, downregulation of this enzyme reduces the lignin content and increases the levels of cell wall-bound phenolic compounds, such as ferulic and sinapic acids (Piquemal et al. 1998; Ralph et al. 1998; Ruel et al. 2009). Overexpression of these genes was confirmed by qRT-PCR (Fig. 2). A tendency to increase the expression of these genes was observed in all four inbred lines, though this increase was only significant $(P$ $<0.05)$ for chitinase-like genes in the inbred line PB130 and was close to significance for the $C C R 2(P=0.06)$ gene in CM151. Upregulation of $C C R 2$ in this inbred line was accompanied by significant lignin increase and slight but no significant reduction of cell-wall-bound phenolics. Thus, these data suggest that overexpression of $C C R 2$ after insect feeding could be responsible for the lignin increase in CM151 while the overexpression of chitinase-like genes may suggest that these genes are involved in the increase of the ferulate and diferulates content after stalk borer attack in PB130.

Phenylpropanoids play an important role in cell-wall strengthening (Bunzel 2010; Grabber 2005; Korkina 2007). The prenylpropanoid biosynthetic pathway is a complex network with several putative regulatory points (Barriere et al. 2009), which makes it difficult to observe a general response. However, a general tendency in the four inbred lines to decrease the levels of $p$-coumarate was observed after stalk borer feeding (Fig. 3A). This reduction was statistically significant for the inbreds PB130 and CM151, which significantly increased diferulic and lignin content, respectively.

Differences in the regulation of some gene functional categories were observed between resistant and susceptible inbred lines. Contrary to resistant inbred lines, EP42 maintains resting levels of expression for functional categories involved in reproduction and even activates general metabolic processes after insect feeding. Interestingly, this inbred line showed the lowest response for the cell-wall reinforcement category. Transcriptome and biochemical analysis indicate that reinforcement of the cell wall is an important inducible defense mechanism in the maize stalk against corn borers predation. Further, the fact that the susceptible line showed the lowest response for this category suggests that the differential response of this functional category could be related to plant resistance. In agreement with this hypothesis, the inbred line PB130 showed much higher activation of the cell-wall reinforcement-related genes than to the other inbreds but very low activation of the defense-related categories, indicating that cell-wall reinforcement could be sufficient for driving plant resistance to stalk borers. Nevertheless, the different HR could also contribute to differentiate between resistant and susceptible genotypes. Moreover, the inbred line EP39 showed high levels of DIMBOA. This is also a novel discovery because DIMBOA was thought to vanish at silking stage.

Curiously, the levels of DIMBOA tend to decrease after insect feeding in the four inbred lines. One explanation for this observation is that DIMBOA is being degraded to produce new compounds with an antibiosis effect. Supporting this hypothesis, Oikawa and associates (2004) showed that the levels of two derivates of DIMBOA (HDMBOA-Glc and MBOA) increase in maize leaves after pathogen attack, and these compounds could also have an antibiosis effect. Nevertheless, the role of these compounds in the resistance against corn borers must be further investigated.

In general terms, data presented herein indicate that the maize stalk responds to the corn borer attack through extensive transcriptome reprogramming and activating defense-related pathways. A significant number of genes belonging to the cellwall reorganization or biogenesis category were upregulated. Until now, the varying levels of cell-wall-bound phenolics present in different genotypes were considered to be constitutive. Transcriptome and biochemical data indicate that the phenylpropanoid pathway is crucial for maize defense upon corn borer feeding, and the $C C R 2$ locus and chitinase-like enzymes could play a central role in regulating this route.

\section{MATERIALS AND METHODS}

\section{Plant material and experimental design.}

Four genetically unrelated maize inbred lines (EP39, EP42, CM151, and PB130) were grown in the greenhouse under controlled conditions. These inbred lines were chosen based on their different level of resistance to attack by $S$. nonagrioides as previously published (Table 2). Four biological replicates of each 
genotype were infested at VT (tasseling) developmental stage with a mass of approximately 40 eggs of $S$. nonagrioides laid on the sheath of the main ear. Another four biological replicates per genotype were used as control. Control and treated plants were separated by seven rows of maize plants to avoid caterpillar migration. A time frame of approximately 10 to 12 days is necessary for egg hatching, movement of neonate larvae down the inner surface of the leaf sheath, and larvae penetration into the stalk. For this reason, to assure that larvae had started to feed on the maize stalk, samples were harvested 15 days after infestation. At harvesting, local damage was observed on the infested plants, albeit not quantified, whereas no damage was observed in control plants. A section of approximately $2 \mathrm{~cm}$ in the upper part of the stalk internode just below the ear was collected from each plant. The leaf sheath was discarded. Samples were immediately frozen in liquid nitrogen and conserved at $-80^{\circ} \mathrm{C}$ for RNA extraction. The rest of the internode was collected and conserved at $-20^{\circ} \mathrm{C}$ for biochemical analysis.

\section{RNA extraction and microarray hybridization.}

Individual sample tissues were ground in liquid nitrogen and the RNA from four biological replicates of each genotype and treatment was extracted using the RiboPure kit (Ambion, Foster City, CA, U.S.A.). The RNA from the four biological replicates per genotype and treatment was equimolarly pooled for microarray hybridization. Standard Affymetrix procedures were used to perform microarray hybridization and analysis. Total RNA (250 ng) was labeled with the GeneChip 3' IVT Express Kit (Affymetrix, Santa Clara, CA, U.S.A.) following the manufacturer's instructions. cRNA ( $15 \mu \mathrm{g}$ per sample) was hybridized on a GeneChip Maize Genome Array (Affymetrix) which interrogates 13,393 maize genes and fluorescence signaling scanned using a GeneChip 3000 scanner (Affymetrix). Data analysis was performed using the Robust Multichip Average tool included in the Affymetrix Expression Console software (Affymetrix).

\section{Microarray data analysis.}

The complete microarray data have been deposited in the National Center for Biotechnology Information Gene Expression Omnibus (GEO) (Edgar et al. 2002) and are accessible through GEO Series accession number GSE28244 Genes with an expression ratio $\leq 0.5$ or $\geq 2$ were considered down- and upregulated, respectively. To identify genes differentially expressed between treatments, a Student's $t$ test (two-sample hypothesis, equal variance) was conducted between $\log _{2}$-transformed expression ratios from infested versus control plants across genotypes. Genes with $P$ values $\leq 0.05$ were considered to be differentially expressed. In addition, the $q$ value method was used to establish the experiment-wise cut-off based on an estimated FDR of 5\%. Data were computed with the QVALUE software (Storey and Tibshirani 2003). Based on $q$ values, a cut-off of 0.044 was used to define differentially expressed genes. To identify functional gene categories differentially regulated in both treatments, a GO analysis across genotypes was performed using the agriGO tool ( $\mathrm{Du}$ et al. 2010). Additionally, GO analyses were also performed for individual inbreds in order to compare gene category expression among genotypes with different level of resistance. Analyses were carried out using the PAGE (Kim and Volsky 2005) with a Hochberg (FDR) multitest adjusted method. This method is able to analyze a long list of microarray probesets, taking into account their expression levels.

\section{qRT-PCR.}

RNA was extracted from four biological replicates of each genotype and treatment. To remove any traces of genomic DNA from RNA extractions, the RNA was treated with a RQ1 RNase-Free DNase (Promega, San Luis Obispo, CA, U.S.A.) following the manufacturer's instructions. Total RNA $(1 \mu \mathrm{g})$ was reverse transcribed using GoScript reverse-transcription system and oligo dT(20) (Promega). qRT-PCR was performed in a $20-\mu l$ reaction with the Fast Start Universe SYBR Green Master (ROX) mix (Roche, Indianapolis, IN, U.S.A.). Actin was used as reference gene. Primer efficiency was calculated using the LingRegPCR software (Ramakers et al. 2003). qRTPCR reactions were carried out on a 7500 Real-Time PCR System (Applied Biosystem, Foster City, CA, U.S.A.). Primers used for qRT-PCR were actin (Fw: CTGTTCTTTCGTTGTAC GCTAGTG; Rv: GGAACCGTGTGGCTCACA), CCR2 (Fw: CGCGTCCTCGCCAAGCTCTT; Rv: GCAGGACCGGCACG AAGTCC), $p C h 2$ (Fw: GCAGCACCTCCGACTACTG; Rv: CAGCAGCATCTGGTTGAAGA), and endochitinase A (Fw: AGGACGCCGTGATCGCGTTC; Rv: CGTTCATCTGGGCG GGGTTGG).

\section{Extraction and quantification \\ of cell-wall phenylpropanoids and ADL.}

Individual, frozen stalk internodes (without the leaf sheath) were lyophilized and ground through a $0.75-\mathrm{mm}$ screen in a Pulveristte 14 rotor mill (Fritsch $\mathrm{GmbH}$, Oberstein, Germany). Plant material $(500 \mathrm{mg}$ ) was extracted in $30 \mathrm{ml}$ of $80 \%$ methanol and mixed with a Polytron mixer (Brinkman Instruments, Westbury, NY, U.S.A.). Samples were extracted for $1 \mathrm{~h}$ and then centrifuged for $10 \mathrm{~min}$ at $1,000 \times \mathrm{g}$. The remaining pellet was then shaken in $20 \mathrm{ml}$ of $2 \mathrm{~N} \mathrm{NaOH}$ under nitrogen flow for $4 \mathrm{~h}$. Digested samples were neutralized with $6 \mathrm{~N} \mathrm{HCl}$, and the $\mathrm{pH}$ was adjusted to 2.0. After centrifugation, the supernatant was collected and the pellet washed twice with distilled water $(10 \mathrm{ml}$ each). Supernatants were pooled and then extracted twice with ethyl acetate $(40 \mathrm{ml}$ each). Collected organic fractions were combined and reduced to dryness using a Speed Vac (Savant Instruments, Holbrook, NY, U.S.A.). The final extract was dissolved in $1.5 \mathrm{ml}$ of methanol and stored at $-20^{\circ} \mathrm{C}$ prior to high-performance liquid chromatography (HPLC) analysis. Phenylpropanoid content was analyzed and quantified as described by Santiago and associates (2006). Total diferulate content was the sum of four isomers (8-5-open DFA, 8-5-benzofuran-DFA, 8-O-4-DFA, and 5-5-DFA). ADL determination was based in the AOAC Official Method 973.18 (AOAC 1997).

Table 2. Characteristics of four maize inbred lines used in this study related to corn borer resistance

\begin{tabular}{|c|c|c|c|c|c|}
\hline Inbred line & Pedigree & Germplasm group & $\begin{array}{l}\text { Field } \\
\text { resistance }^{\mathrm{a}}\end{array}$ & Antibiosis $^{b}$ & Characteristics $^{c}$ \\
\hline EP39 & Fino & European flint & Resistant & Resistant & Thick rind; highly resistant to node penetration \\
\hline EP42 & Tomiño & European flint & Susceptible & Susceptible & Long internode meristematic area \\
\hline PB130 & Rojo vinoso de Aragon & European flint & Resistant & Intermediate & Thick pith parenchyma interlumen; thin rind \\
\hline CM151 & $\mathrm{Mt} 42 \times \mathrm{Wf}^{2}$ & Reid (non-stiff stalk) & Resistant & Resistant & $\begin{array}{l}\text { Thick pith parenchyma interlumen; highly resistant } \\
\text { to node penetration }\end{array}$ \\
\hline
\end{tabular}

\footnotetext{
${ }^{a}$ Based on data published by Butron and associates (1999).

${ }^{\mathrm{b}}$ Based on data published by Ordas and associates (2002).

${ }^{\mathrm{c}}$ Based on data published by Santiago and associates (2003).
} 
Extraction and quantification of DIMBOA.

Individual frozen stalk internodes (without the leaf sheath) (100 mg each) were weighed into screw-capped 15-ml polypropylene Falcon tubes, and $5 \mathrm{ml}$ of HPLC-grade methanol and $50 \mu \mathrm{l}$ of acetic acid were added to each tube. The tubes were vortexed and placed in a sonicator water bath for $60 \mathrm{~min}$ at $60^{\circ} \mathrm{C}$. The supernatant $(0.5 \mathrm{ml})$ was combined with $0.5 \mathrm{ml}$ of distilled water in a microcentrifuge tube, vortexed, and centrifuged for $5 \mathrm{~min}$ at 13,000 rpm. The supernatants were transferred into auto-sample vials for analysis by HPLC. Analyses were performed using a 2690 Waters Separations Module (Waters, Milford, MA, U.S.A.) equipped with a 996 Photodiode Array Detector with a Waters YMC ODS-AM narrow-bore column (100 by $2 \mathrm{~mm}$ i.d.; $3 \mu \mathrm{M}$ particle size). Elution conditions with a mobile phase system of acetotrinile (solvent A) and trifluoroacetic acid $(0.05 \%)$ in water (solvent $\mathrm{B}$ ) were as follows: initial conditions 10:90 (A:B), changing to 30:70 in $3.5 \mathrm{~min}$, then to $32: 68$ in $6.5 \mathrm{~min}$, then to $100: 0$ in $4 \mathrm{~min}$, then isocratic elution with 100:0 for $4.5 \mathrm{~min}$, finally returning to the initial conditions in $3 \mathrm{~min}$. The mobile phase flow rate was 0.3 $\mathrm{ml} / \mathrm{min}$ and the total analysis time was $21.5 \mathrm{~min}$. The sample injection volume was $4 \mu \mathrm{l}$, and the elution profiles were monitored online by UV absorbance at 325 and $254 \mathrm{~nm}$. Retention time was compared with freshly prepared standard solutions. Standard of DIMBOA was provided by C. Souto from the University of Vigo (Spain).

\section{ACKNOWLEDGMENTS}

We thank the staff of the Unidad de Genómica (UCM) for microarray hybridization; A. Carballeda, R. Díaz, and S. Poceiro for technical support; and C. Souto for DIMBOA standard. This work was supported by the Spanish National Plan for Research and Development (grant number AGL2009-09611). V. M. Rodriguez acknowledges a contract from the Spanish National Research Council (JAE-DOC program) and R. Santiago acknowledges a contract from the Autonomous Government of Galicia (Isidro Parga Pondal program).

\section{LITERATURE CITED}

Agrawal, A. A. 1998. Induced responses to herbivory and increased plant performance. Science 279:1201-1202.

AOAC. 1997. Fibre (acid detergent) and lignin (H2SO4) in animal feed Pages 28-29 in: Official Methods of Analysis. Association of Official Analytical Chemists International, Arlington, VA, U.S.A.

Barriere, Y., Mechin, V., Lafarguette, F., Manicacci, D., Guillon, F., Wang, H., Lauressergues, D., Pichon, M., Bosio, M., and Tatout, C. 2009. Toward the discovery of maize cell wall genes involved in shage quality and capacity to biofuel production. Maydica 54:161-198.

Bergvinson, D. J., Arnason, J. T., and Hamilton, R. I. 1997. Phytochemical changes during recurrent selection for resistance to the European corn borer. Crop Sci. 37:1567-1572.

Bowles, D. J. 1990. Defense-related proteins in higher plants. Annu. Rev. Biochem. 59:873-907.

Bunzel, M. 2010. Chemistry and occurrence of hydroxycinnamate oligomers. Phytochem. Rev. 9:47-64.

Butron, A., Malvar, R. A., Cartea, M. E., Ordas, A., and Velasco, P. 1999. Resistance of maize inbreds to pink stem borer. Crop Sci. 39:102-107.

Carpita, N. C., Defernez, M., Findlay, K., Wells, B., Shoue, D. A., Catchpole, G., Wilson, R. H., and McCann, M. C. 2001. Cell wall architecture of the elongating maize coleoptile. Plant Physiol. 127:551-565.

Cordero, M. J., Raventos, D., and San Segundo, B. 1994. Expression of a maize proteinase inhibitor gene is induced in response to wounding and fungal infection: Systemic wound-response of a monocot gene. Plant J. 6:141-150.

Du, Z., Zhou, X., Ling, Y., Zhang, Z., and Su, Z. 2010. agriGO: A GO analysis toolkit for the agricultural community. Nucleic Acids Res. 38 (Suppl.):W64-70.

Edgar, R., Domrachev, M., and Lash, A. E. 2002. Gene Expression Omnibus: NCBI gene expression and hybridization array data repository. Nucleic Acids Res. 30:207-210.

Finaev, D. 2007. Some aspects of cellulose biosynthesis. Biol. Plant. $51: 407-413$
Futuyma, D. J., and Agrawal, A. A. 2009. Macroevolution and the biological diversity of plants and herbivores. Proc. Natl. Acad. Sci. U.S.A. 106:18054-18061.

Gilardoni, P. A., Schuck, S., Jungling, R., Rotter, B., Baldwin, I. T., and Bonaventure, G. 2010. SuperSAGE analysis of the Nicotiana attenuata transcriptome after fatty acid-amino acid elicitation (FAC): Identification of early mediators of insect responses. BMC Plant Biol. 10:66.

Govind, G., Mittapalli, O., Griebel, T., Allmann, S., Bocker, S., and Baldwin, I. T. 2010. Unbiased transcriptional comparisons of generalist and specialist herbivores feeding on progressively defenseless Nicotiana attenuata plants. PLoS One 5:e8735.

Grabber, J. H. 2005. How do lignin composition, structure, and cross-linking affect degradability? A review of cell wall model studies. Crop Sci. 45:820-831.

Graham, M. Y., Weidner, J., Wheeler, K., Pelow, M. J., and Graham, T. L. 2003. Induced expression of pathogenesis-related protein genes in soybean by wounding and the Phytophthora sojae cell wall glucan elicitor. Physiol. Mol. Plant Pathol. 63:141-149.

Guillaumie, S., San-Clemente, H., Deswarte, C., Martinez, Y., Lapierre, C., Murigneux, A., Barriere, Y., Pichon, M., and Goffner, D. 2007. MAIZEWALL. Database and developmental gene expression profiling of cell wall biosynthesis and assembly in maize. Plant Physiol. 143:339-363.

Hermans, C., Porco, S., Verbruggen, N., and Bush, D. R. 2010. Chitinaselike protein CTL1 plays a role in altering root system architecture in response to multiple environmental conditions. Plant Physiol. 152:904917.

Hermsmeier, D., Schittko, U., and Baldwin, I. T. 2001. Molecular interactions between the specialist herbivore Manduca sexta (Lepidoptera, Sphingidae) and its natural host Nicotiana attenuata. I. Large-scale changes in the accumulation of growth- and defense-related plant mRNAs. Plant Physiol. 125:683-700.

Ishii, T. 1997. Structure and functions of feruloylated polysaccharides. Plant Sci. 127:111-127.

Journot-Catalino, N., Somssich, I. E., Roby, D., and Kroj, T. 2006. The transcription factors WRKY11 and WRKY17 act as negative regulators of basal resistance in Arabidopsis thaliana. Plant Cell 18:3289-3302.

Jung, H.J. 2003. Maize stem tissues: Ferulate deposition in developing internode cell walls. Phytochemistry 63:543-549.

Kaur, H., Heinzel, N., Schottner, M., Baldwin, I. T., and Galis, I. 2010. R2R3-NaMYB8 regulates the accumulation of phenylpropanoid-polyamine conjugates, which are essential for local and systemic defense against insect herbivores in Nicotiana attenuata. Plant Physiol. 152:1731-1747.

Kfir, R., Overholt, W. A., Khan, Z. R., and Polaszek, A. 2002. Biology and management of economically important lepidopteran cereal stem borers in Africa. Annu. Rev. Entomol. 47:701-731.

Kim, S. Y., and Volsky, D. J. 2005. PAGE: Parametric analysis of gene set enrichment. BMC Bioinf. 6:144.

Klun, J. A., Tipton, C. L., and Brindley, T. A. 1967. 2,4-Dihydroxy-7methoxy-1,4-benzoxazin-3-1 (DIMBOA) an active agent in resistance of maize to European corn borer. J. Econ. Entomol. 60:1529-1533.

Korkina, L. G. 2007. Phenylpropanoids as naturally occurring antioxidants: From plant defense to human health. Cell. Mol. Biol. 53:15-25.

Malvar, R. A., Butrón, A., Ordás, B., and Santiago, R. 2008. Causes of natural resistance to stem borers in maize, Pages 57-100 in: Crop Protection Research Advances. E. N. Burton and P. V. Williams, eds. Nova Science Publishers, Inc., Hauppauge, NY, U.S.A.

Oikawa, A., Ishihara, A., Tanaka, C., Mori, N., Tsuda, M., and Iwamura, H. 2004. Accumulation of HDMBOA-Glc is induced by biotic stresses prior to the release of MBOA in maize leaves. Phytochemistry 65:29953001 .

Ordas, B., Butron, A., Soengas, P., Ordas, A., and Malvar, R. A. 2002. Antibiosis of the pith maize to Sesamia nonagrioides (Lepidoptera: Noctuidae). J. Econ. Entomol. 95:1044-1048.

Ostrander, B. M., and Coors, J. G. 1997. Relationship between plant composition and European corn borer resistance in three maize populations. Crop Sci. 37:1741-1745.

Park, J. H., Halitschke, R., Kim, H. B., Baldwin, I. T., Feldmann, K. A., and Feyereisen, R. 2002. A knock-out mutation in allene oxide synthase results in male sterility and defective wound signal transduction in Arabidopsis due to a block in jasmonic acid biosynthesis. Plant J. 31:1-12.

Patil, V. R., and Widholm, J. M. 1997. Possible correlation between increased vigour and chitinase activity expression in tobacco. J. Exp. Bot. 48:1943-1950.

Philippe, R. N., Ralph, S. G., Kulheim, C., Jancsik, S. I., and Bohlmann, J. 2009. Poplar defense against insects: Genome analysis, full-length cDNA cloning, and transcriptome and protein analysis of the poplar Kunitz-type protease inhibitor family. New Phytol. 184:865-884.

Pichon, M., Courbou, I., Beckert, M., Boudet, A. M., and Grima-Pettenati, 
J. 1998. Cloning and characterization of two maize cDNAs encoding Cinnamoyl-CoA reductase (CCR) and differential expression of the corresponding genes. Plant Mol. Biol. 38:671-676.

Piquemal, J., Lapierre, C., Myton, K., O’Connell, A., Schuch, W., GrimaPettenati, J., and Boudet, A. M. 1998. Down-regulation of cinnamoylCoA reductase induces significant changes of lignin profiles in transgenic tobacco plants. Plant J. 13:71-83.

Ralph, J., Hatfield, R. D., Piquemal, J., Yahiaoui, N., Pean, M., Lapierre, C., and Boudet, A. M. 1998. NMR characterization of altered lignins extracted from tobacco plants down-regulated for lignification enzymes cinnamylalcohol dehydrogenase and cinnamoyl-CoA reductase. Proc. Natl. Acad. Sci. U.S.A. 95:12803-12808.

Ramakers, C., Ruijter, J. M., Deprez, R. H., and Moorman, A. F. 2003. Assumption-free analysis of quantitative real-time polymerase chain reaction (PCR) data. Neurosci. Lett. 339:62-66.

Reid, L. M., Arnason, J. T., Nozzolillo, C., and Hamilton, R. I. 1991. Laboratory and field-resistance to the European corn-borer in maize germplasm. Crop Sci. 31:1496-1502.

Reymond, P., Bodenhausen, N., Van Poecke, R. M. P., Krishnamurthy, V., Dicke, M., and Farmer, E. E. 2004. A conserved transcript pattern in response to a specialist and a generalist herbivore. Plant Cell 16:31323147.

Robinson, J. F., Klun, J. A., Guthrie, W. D., and Brindley, T. A. 1982. European corn-borer (Lepidoptera, Pyralidae) leaf feeding resistanceDIMBOA bioassays. J. Kans. Entomol. Soc. 55:357-364.

Rohrmeier, T., and Lehle, L. 1993. WIP1, a wound-inducible gene from maize with homology to Bowman-Birk proteinase inhibitors. Plant Mol. Biol. 22:783-792.

Ruel, K., Berrio-Sierra, J., Derikvand, M. M., Pollet, B., Thevenin, J., Lapierre, C., Jouanin, L., and Joseleau, J. P. 2009. Impact of CCR1 silencing on the assembly of lignified secondary walls in Arabidopsis thaliana. New Phytol. 184:99-113.

Santiago, R., Souto, X. C., Sotelo, J., Butron, A., and Malvar, R. A. 2003. Relationship between maize stem structural characteristics and resistance to pink stem borer (Lepidoptera: Noctuidae) attack. J. Econ. Entomol. 96:1563-1570.

Santiago, R., Butron, A., Arnason, J. T., Reid, L. M., Souto, X. C., and Malvar, R. A. 2006. Putative role of pith cell wall phenylpropanoids in Sesamia nonagrioides (Lepidoptera: Noctuidae) resistance. J. Agric. Food Chem. 54:2274-2279.
Santiago, R., Sandoya, G., Butron, A., Barros, J., and Malvar, R. A. 2008 Changes in phenolic concentrations during recurrent selection for resistance to the Mediterranean corn borer (Sesamia nonagrioides Lef.). J. Agric. Food Chem. 56:8017-8022.

Storey, J. D., and Tibshirani, R. 2003. Statistical significance for genomewide studies. Proc. Natl. Acad. Sci. U.S.A. 100:9440-9445.

Wan, J., Dunning, F. M., and Bent, A. F. 2002. Probing plant-pathogen interactions and downstream defense signaling using DNA microarrays. Funct. Integr. Genomics 2:259-273.

Wang, D., Guo, Y., Wu, C., Yang, G., Li, Y., and Zheng, C. 2008. Genomewide analysis of $\mathrm{CCCH}$ zinc finger family in Arabidopsis and rice. BMC Genomics 9:44.

Wei, Z., Hu, W., Lin, Q., Cheng, X., Tong, M., Zhu, L., Chen, R., and He G. 2009. Understanding rice plant resistance to the Brown Planthopper (Nilaparvata lugens): A proteomic approach. Proteomics 9:2798-2808.

Xie, Q., Guo, H. S., Dallman, G., Fang, S., Weissman, A. M., and Chua, N. H. 2002. SINAT5 promotes ubiquitin-related degradation of NAC1 to attenuate auxin signals. Nature 419:167-170.

Xu, X., Chen, C., Fan, B., and Chen, Z. 2006. Physical and functional interactions between pathogen-induced Arabidopsis WRKY18, WRKY40, and WRKY60 transcription factors. Plant Cell 18:13101326

Zhang, D. S., Hrmova, M., Wan, C. H., Wu, C. F., Balzen, J., Cai, W. Wang, J., Densmore, L. D., Fincher, G. B., Zhang, H., and Haigler, C.H. 2004. Members of a new group of chitinase-like genes are expressed preferentially in cotton cells with secondary walls. Plant Mol. Biol. 54:353-372.

Zhang, Y. J., and Wang, L. J. 2005. The WRKY transcription factor superfamily: Its origin in eukaryotes and expansion in plants. BMC Evol. Biol. 5:1.

Zhou, G., Qi, J., Ren, N., Cheng, J., Erb, M., Mao, B., and Lou, Y. 2009. Silencing OsHI-LOX makes rice more susceptible to chewing herbivores, but enhances resistance to a phloem feeder. Plant J. 60:638-648.

\section{AUTHOR-RECOMMENDED INTERNET RESOURCES}

MaizeSequence database: www.maizesequence.org

NCBI GEO Series GSE28244webpage: www.ncbi.nlm.nih.gov/geo/query/acc.cgi?acc=GSE28244 